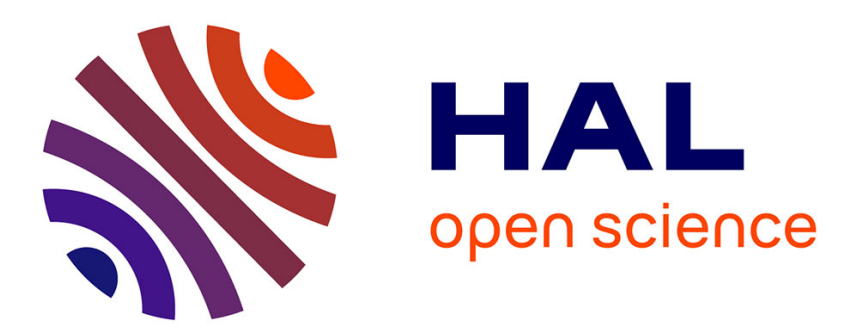

\title{
Fatal overdose after ingestion of a transdermal fentanyl patch in two non-human primates
}

Jack-Yves Deschamps, Jean-Michel Gaulier, Guillaume Podevin, Yan Cherel, Nicolas Ferry, Françoise Roux

\section{- To cite this version:}

Jack-Yves Deschamps, Jean-Michel Gaulier, Guillaume Podevin, Yan Cherel, Nicolas Ferry, et al.. Fatal overdose after ingestion of a transdermal fentanyl patch in two non-human primates. Veterinary Anaesthesia and Analgesia, 2012, pp.NC. hal-01137011

\section{HAL Id: hal-01137011 https://hal.science/hal-01137011}

Submitted on 30 Mar 2015

HAL is a multi-disciplinary open access archive for the deposit and dissemination of scientific research documents, whether they are published or not. The documents may come from teaching and research institutions in France or abroad, or from public or private research centers.
L'archive ouverte pluridisciplinaire HAL, est destinée au dépôt et à la diffusion de documents scientifiques de niveau recherche, publiés ou non, émanant des établissements d'enseignement et de recherche français ou étrangers, des laboratoires publics ou privés. 


\title{
CASE REPORT
}

\section{Fatal overdose after ingestion of a transdermal fentanyl patch in two non-human primates}

\author{
Jack-Yves Deschamps*, Jean-Michel Gaulier†, Guillaume Podevinł, Yan Cherel§, Nicolas Ferry \& \& \\ Françoise A Roux** \\ *Emergency and Critical Care Unit, LUNAM University, ONIRIS, Nantes-Atlantic College of Veterinary Medicine, Food \\ Science and Engineering - La Chantrerie, Nantes, France \\ $\dagger$ Department of Pharmacology and Toxicology, University Hospital, Limoges, France \\ †Department of Pediatric Surgery, University Hospital, Angers, France \\ §Department of Pathology, LUNAM University, Oniris, Nantes-Atlantic College of Veterinary Medicine, Food Science and \\ Engineering - La Chantrerie, Nantes, France \\ -INSERM UMR S948, Biothérapies hépatiques, CHU Hotel Dieu, Nantes Cedex, France \\ **Emergency and Critical Care Unit, Alfort School of Veterinary Medicine, Maisons-Alfort Cedex, France
}

Correspondence: Jack-Yves Deschamps, Emergency and Critical Care Unit, LUNAM University, ONIRIS, Nantes-Atlantic College of Veterinary Medicine, Food Science and Engineering - La Chantrerie, BP 40706, 44307 NANTES, France. E-mail: jack.deschamps@ oniris-nantes.fr

\begin{abstract}
Case history and presentation Two non-human primates (Macaca fascicularis), weight $3.5 \mathrm{~kg}$, enrolled in an experimental protocol received a $25 \mu$ hour $^{-1}$ transdermal fentanyl patch for postoperative analgesia. The following day both animals were clinically normal, but after a new induction of anaesthesia with ketamine, they developed severe and prolonged respiratory distress, profound coma and myosis.
\end{abstract}

Management and follow-up Attempted reversal with naloxone was ineffective. After several hours of ventilation, both primates eventually died, 7 and 15 hours after ketamine injection, respectively. In both cases, the patch was discovered in the animal's cheek pouch. Subsequent fentanyl serum concentration measurements (8.29 and $\left.14.80 \mu \mathrm{g} \mathrm{L}^{-1}\right)$ confirmed fentanyl overdose.

Conclusions This report of two fatal intoxications in non-human primates secondary to ingestion of a transdermal fentanyl patch demonstrates that this method of analgesia is inappropriate for non-human primates, because of their tendency to chew almost anything they can reach.

Keywords fentanyl patch, opioids non human primate.

\section{Case history}

Two non-human primates, crab-eating macaque (Macaca fascicularis), were enrolled in an experimental protocol to implement a clinical trial for gene therapy of Crigler-Najjar disease. The aim of this study was to assess whether recombinant adeno-associated virus from serotype 8 are able to transduce hepatocytes after delivery to the hepatic artery by a surgical approach. Both animals were 6 month-old male primates weighing $3.5 \mathrm{~kg}$. Surgery was performed on the same day for both animals, at 10:00 A.M. and 1:00 P.M., respectively. Induction of anaesthesia consisted of an intramuscular (IM) injection of a combination of $30 \mu \mathrm{g} \mathrm{kg}^{-1}$ medetomidine (Domitor; Pfizer, France) and $7 \mathrm{mg}$ $\mathrm{kg}^{-1}$ ketamine (Imalgène; Mérial, France), mixed in one syringe. After endotracheal intubation, an intravenous (IV) catheter was placed in the 
saphenous vein, and lactated Ringer's solution was infused at $10 \mathrm{~mL} \mathrm{~kg}^{-1}$ hour $^{-1}$ during the entire procedure. Analgesia was provided by morphine at $0.1 \mathrm{mg} \mathrm{kg}^{-1}$ (Morphine; Cooper, France) administered subcutaneously at induction of anaesthesia. No additional dose was required during surgery. Anaesthesia was maintained with $1.5 \%$ isoflurane (Forène; Abbott, France) delivered in oxygen at $1 \mathrm{~L} \mathrm{minute}^{-1}$ via a non-rebreathing system. Respiration was spontaneous throughout the procedure. The primates were monitored by close observation, respiratory rate and body temperature measurement, electrocardiography, pulse oximetry and capnography. Arterial blood pressure was not monitored. Parameters were remarkably constant, and within normal values. Total duration of anaesthesia was 2.5 hours.

Contrary to our usual practice, which is to manage postoperative pain by oral morphine in a banana only if pain is suspected, a $25 \mu \mathrm{g} \mathrm{hour}^{-1}$ transdermal fentanyl patch (Durogésic; Janssen Cilag, France), a reservoir-type patch, was placed on a hairless area of skin of the thoracic wall, without disinfection. Adhesion appeared to be perfect, and no additional protection was applied. In order to provide analgesia until the transdermal patch took effect, a second $0.1 \mathrm{mg} \mathrm{kg}^{-1}$ subcutaneous dose of morphine was administered. Both primates were conscious within a few minutes after administration of isoflurane ceased. One hour after recovery both primates were alert and climbing the bars of their cages.

The following day at 9:00 A.M. both animals were still apparently normal. Twenty-three and 20 hours respectively after the first anaesthesia, they were re-anaesthetized in order to obtain a blood sample. By IM injection they both received $10 \mathrm{mg} \mathrm{kg}^{-1}$ ketamine alone, without medetomidine. No instrumental monitoring is normally used for such procedures in our centre. Twenty minutes after the injection, when the animals would usually be regaining consciousness, severe bradypnea was observed in both primates, followed by apnoea. Endotracheal intubation was performed in both animals and assisted ventilation commenced with $100 \%$ oxygen. IV catheters were placed and monitoring was instituted as described for the first anaesthesia. The respiratory arrest was associated with coma and myosis. Body temperature remained constant, but an upper-body-warming blanket was placed. No other abnormality was noted. Repeated IV injections of $1 \mathrm{mg} \mathrm{kg}^{-1}$ doxap- ram (Dopram, Vétoquinol, France) were without visible effects.

At 1:00 P.M., 4 hours after ketamine administration, it was remembered that fentanyl patches had been placed the day before. The animal keepers told us that the patches had not been in place in the morning, prior to the second anaesthesia induction; they had assumed that they were in the sawdust in the cages. Because the dosage of the patch was high (25 $\mathrm{g} \mathrm{hour}^{-1}$ for a $3.5 \mathrm{~kg}$ animal), we suspected transdermal intoxication with fentanyl. At that time we did not consider oral intoxication.

Shortly after IV administration of $0.01 \mathrm{mg} \mathrm{kg}^{-1}$ of naloxone (Narcan; Serb A.A.S., France), a competitive $\mu$-opioid receptor antagonist, one primate became more alert and began to moan, but he rapidly returned comatose. No arousal was observed with the second primate. Many subsequent injections of naloxone had no effect in either primate, nor did repeated injections of doxapram. Several vials of naloxone from the same box were used. As a last resort, an IV injection of $0.4 \mathrm{mg} \mathrm{kg}^{-1}$ butorphanol (Dolorex; Intervet, France), a $\mu$-opioid receptor antagonist, was given, without visible effect. For all drugs used, the expiry date had not been reached.

At 2:00 P.M., 5 hours after ketamine injection, both primates were still unconscious, but began to breathe spontaneously. Respiration was rapid and shallow; the ECG remained normal, with no bradycardia or arrhythmias.

Six hours after ketamine injection, one primate presented with a new, prolonged period of apnoea. Assisted ventilation was stopped 1 hour later, and the animal died shortly thereafter. The second primate, still unconscious, continued to breathe spontaneously but died at midnight, 15 hours after ketamine administration.

A thorough search for the two patches in the sawdust of the cages was unsuccessful. Post-mortem examination of the cadavers did not reveal any abnormalities: the surgical site was unremarkable, there was no haemorrhage, pneumothorax, pulmonary oedema or tracheal injury; stomach and bowel were empty. A careful examination of the mouth led to the discovery of a patch in each animal's cheek pouch.

Assays for fentanyl and its main metabolite (norfentanyl) were performed on the blood samples collected just before respiratory arrest (20 hours after transdermal fentanyl patch application). Determination of fentanyl and norfentanyl concentrations in serum was accomplished using a liquid 
chromatography-tandem mass spectrometry method. The observed concentrations in the two primates' plasma were 8.29 and $14.80 \mu \mathrm{g} \mathrm{L}^{-1}$ for fentanyl and 0.68 and $1.86 \mu \mathrm{g} \mathrm{L}^{-1}$ for norfentanyl.

Six other primates were enrolled in the protocol; transdermal fentanyl patches were not used. No complications were observed; viral preparation and surgical procedure do not seem to have been involved in these deaths.

\section{Discussion}

The clinical history, symptoms, post-mortem findings and blood concentrations of fentanyl and its metabolite demonstrate that both primates died from an overdose of fentanyl after ingestion of a transdermal patch. This is the first such report in animals. In veterinary medicine, a case report described a nonfatal suspected overdose by transmucosal or oral absorption of the reservoir of a transdermal fentanyl patch (transdermal therapeutic system, or TTS) in a dog. This animal presented with sedation, and recovered without the use of naloxone (Schmiedt \& Bjorling 2007); the highest fentanyl serum concentration $\left(1.7 \mu \mathrm{g} \mathrm{L}^{-1}\right)$ was slightly higher than those observed for analgesia $\left(0.7 \mu \mathrm{g} \mathrm{L}^{-1}\right)$ (Egger et al. 1998), but lower than those regularly reported in humans with fatal intoxications.

A fatal accidental intoxication after oral ingestion was reported in a child, a 1 year old girl weighing $11 \mathrm{~kg}$, who was found dead 2 hours after being put to bed (Teske et al. 2007). Autopsy revealed a $25 \mu$ hour $^{-1}$ fentanyl TTS among the stomach contents. Post-mortem blood concentration of fentanyl was $5.6 \mu \mathrm{g} \mathrm{L}^{-1}$. Investigation revealed that the childminder was being treated with a $25 \mu$ hour $^{-1}$ fentanyl TTS. She normally replaced the patch every 3 days and disposed of it within the package in the household waste. On that day, the used TTS was apparently dropped on the floor, from where the child ingested it. This report emphasizes the fact that a significant, potentially lethal, amount of fentanyl persists within a used patch. Each fentanyl TTS contains enough fentanyl to be lethal (Nelson \& Schwaner 2009). After 3 days of continuous use, $28-84.4 \%$ of the original contents of a patch remains - often higher than the lethal dose (Marquardt et al. 1995). In dogs, after 72 hours attachment, patches still contained an average of $83 \%$ of the original amount (Reed et al. 2011).
Transmusosal absorption is much higher than gastric absorption and there is no first pass through the liver. If the primates had eaten the patch instead of keeping them in the cheek pouch, the outcome might have been different. In humans, several cases of intoxication in patients who used TTS as oral mucosal medication for analgesic purpose have been reported (Liappas et al. 2004; van Rijswijk \& van Guldener 2006; Dale et al. 2009).

In humans, after a $25 \mu$ hour $^{-1}$ fentanyl TTS treatment, the mean concentration of fentanyl observed during the following 24 hour period is $0.7 \mu \mathrm{g} \mathrm{L}^{-1}$ (maximum about $1.0 \mu \mathrm{g} \mathrm{L}^{-1}$ ) (Jeal \& Benfield 1997). Generally, data from reported fatal overdose cases suggest that a fentanyl blood concentration above $3 \mu \mathrm{g} \mathrm{L}^{-1}$ is consistent with the hypothesis of a fentanyl overdose (Henderson 1983). By analogy with humans, the observed blood concentrations of fentanyl, 8.29 and $14.80 \mu \mathrm{g} \mathrm{L}^{-1}$ in the present case, attests to the role of fentanyl in the death of both primates.

Respiratory arrest is the most common cause of death due to fentanyl intoxication (Moon \& Chun 2011). Ketamine triggered the first symptoms of respiratory distress, and potentiated the secondary effects of the fentanyl; surprisingly, given the severity of the events, neither primate had any obvious symptoms prior to injection of ketamine. The absence of effect of the naloxone is another surprising observation; presumably the serum concentration of fentanyl was too high to be antagonized (blood levels were 1.5 and almost 3 times higher than the child who died). Morover, as the patches remained in the check pouches, there may have been further absorption; blood levels at death could have been higher than those measured.

Several factors contributed to the accident:

- The desire to provide excellent analgesia for laboratory animals led to using pre-emptive analgesia, without pain assessment;

- The change in our usual procedures;

- The high dose of the TTS: a $12.5 \mu \mathrm{g} \mathrm{hour}^{-1}$ patch would have been enough for an animal of this weight, especially since the surgery was not particularly painful;

- The lack of protection for the patch;

- The failure to note the absence of the patches;

- The ketamine injection triggered and potentiated the fentanyl's side effects;

- The failure to take primate behaviour into account, especially their propensity for handling and chewing objects. 


\section{Conclusion}

This first report of two fatal intoxications in nonhuman primates after ingestion of a fentanyl TTS emphasizes that this method of analgesia is not appropriate for primates, because of their tendency to chew almost anything they can reach.

\section{Acknowledgements}

This work was supported by grant from AFM (Association Française contre les Myopathies). We thank the staff of the Gene and Cellular Therapy Centre of Boisbonne at Nantes Veterinary School, France.

\section{References}

Dale E, Ashby F, Seelam K (2009) Report of a patient chewing fentanyl patches who was titrated onto methadone. BMJ Case Rep 2009, 1454.

Egger CM, Duke T, Archer J et al. (1998) Comparison of plasma fentanyl concentrations by using three transdermal fentanyl patch sizes in dogs. Vet Surg 27, 159166.

Henderson GL (1983) Blood concentrations of fentanyl and its analogs in overdose victims. Proc West Pharmacol Soc 26, 287-290.
Jeal W, Benfield P (1997) Transdermal fentanyl. A review of its pharmacological properties and therapeutic efficacy in pain control. Drugs 53, 109-138.

Liappas IA, Dimopoulos NP, Mellos E et al. (2004) Oral transmucosal abuse of transdermal fentanyl. J Psychopharmacol 18, 277-280.

Marquardt KA, Tharratt RS, Musallam NA (1995) Fentanyl remaining in a transdermal system following three days of continuous use. Ann Pharmacother 29, 969-971.

Moon JM, Chun BJ (2011) Fentanyl intoxication caused by abuse of transdermal fentanyl. J Emerg Med 40, 37-40.

Nelson L, Schwaner R (2009) Transdermal fentanyl: pharmacology and toxicology. J Med Toxicol 5, 230-241.

Reed F, Burrow R, Poels KL et al. (2011) Evaluation of transdermal fentanyl patch attachment in dogs and analysis of residual fentanyl content following removal. Vet Anaesth Analg 38, 407-412.

van Rijswijk R, van Guldener C (2006) A delirious patient with opioid intoxication after chewing a fentanyl patch. J Am Geriatr Soc 54, 1298-1299.

Schmiedt CW, Bjorling DE (2007) Accidental prehension and suspected transmucosal or oral absorption of fentanyl from a transdermal patch in a dog. Vet Anaesth Analg 34, 70-73.

Teske J, Weller JP, Larsch K et al. (2007) Fatal outcome in a child after ingestion of a transdermal fentanyl patch. Int J Legal Med 121, 147-151.

Received 15 January 2012; accepted 12 March 2012. 